\title{
Touching Outward: Art- Making at the Seam Where Care Meets Risk
}

\section{ALYS LONGLEY (D) \\ KAREN FISHER (D) \\ GABBY O'CONNOR (D)}

JAMES HUTCHINSON

*Author affiliations can be found in the back matter of this article

\section{बस्म \\ Open Library of Humanities}

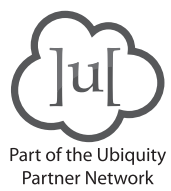

CORRESPONDING AUTHOR:

\section{Alys Longley}

University of Auckland, NZ

a.longley@auckland.ac.nz

\section{KEYWORDS:}

Marine Sustainability; Ecology; Risk; Poetic Inquiry; Transdisciplinary Research; Weak Theory; Oceans; Thinking with Water; Sound as Touch

TO CITE THIS ARTICLE: Longley, A, Fisher, K, O'Connor, G and Hutchinson, J. 2021.

Touching Outward: Art-Making at the Seam Where Care Meets Risk. Journal of Embodied Research, 4(1): 1 (21:14). DOI: https://doi.org/10.16995/jer.34

and oceans in Aotearoa New Zealand. Embodiment is at the heart of these collaborative projects. We think of how embodied experience folds through imagination to create potentials for unseating convention, perspective, actuality, reproducibility, common sense.

Our transdisciplinary project was developed by four artist-researchers from diverse disciplinary backgrounds, each of us working beyond our conventional practices- a geographer, a performance maker, a visual artist, and a film maker. We are moving between philosophy, social science, pedagogy, ecology, performance, poetry, installation and film. The framework of weak theory provides a kind of permission to reach beyond the conventions of our disciplines, to make space for modes of embodied 
research that entangle abstract and material concepts through relational, artistic and pedagogical intentions.

Throughout the process and development of this artistic research, we question where a body begins and ends, how the voice as a vibratile force touches through time and space, and how moving image as a body of textures and cuts might contribute to methods of weak theory (Wright, 2015) and transdisciplinary creative practice.

\section{VIDEO ARTICLE}

Available to view here: https://doi.org/10.16995/jer.34.

Available for download here: https://doi.org/10.16995/jer.34.s1.

\section{STILLS FROM THE VIDEO ARTICLE}
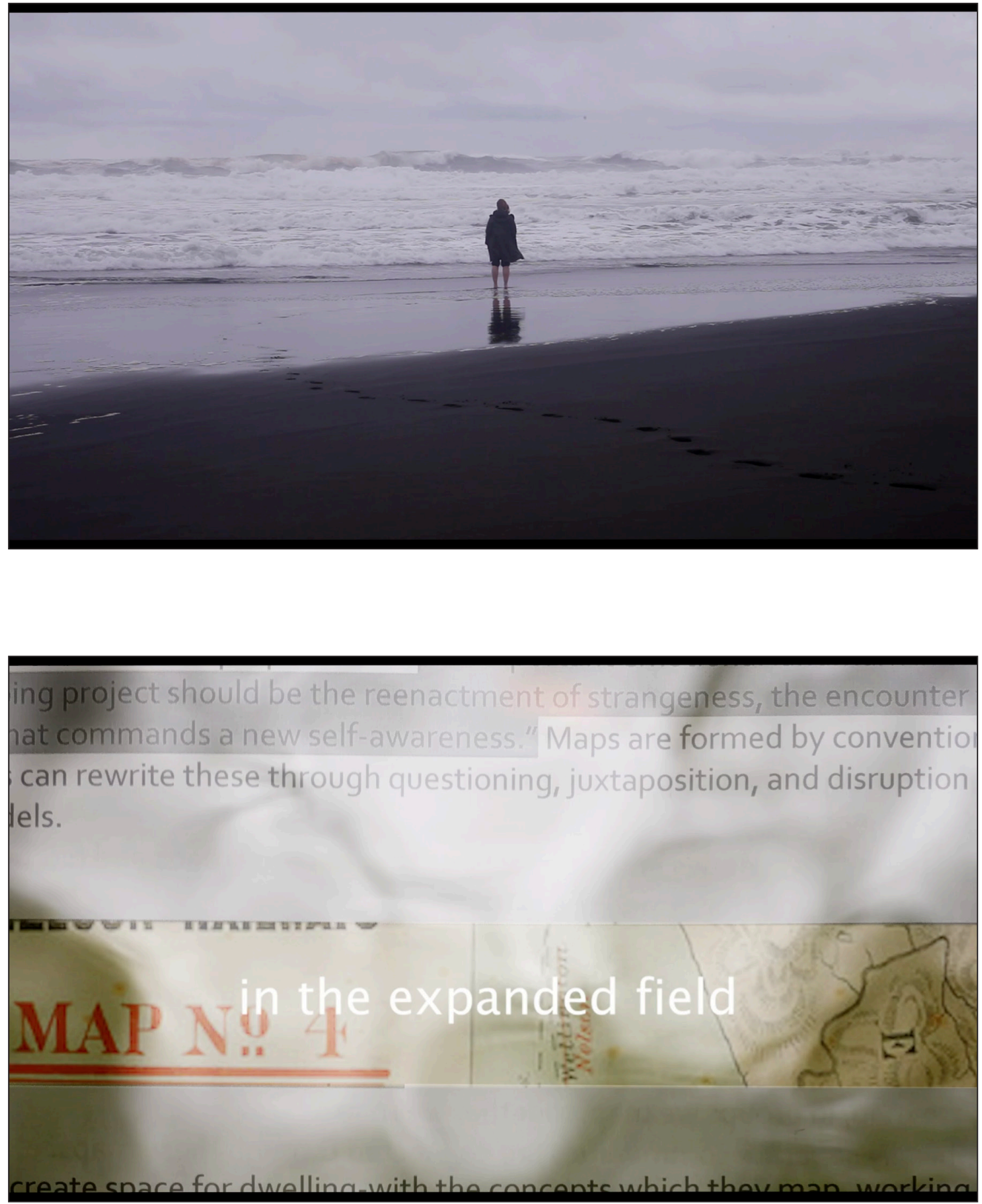

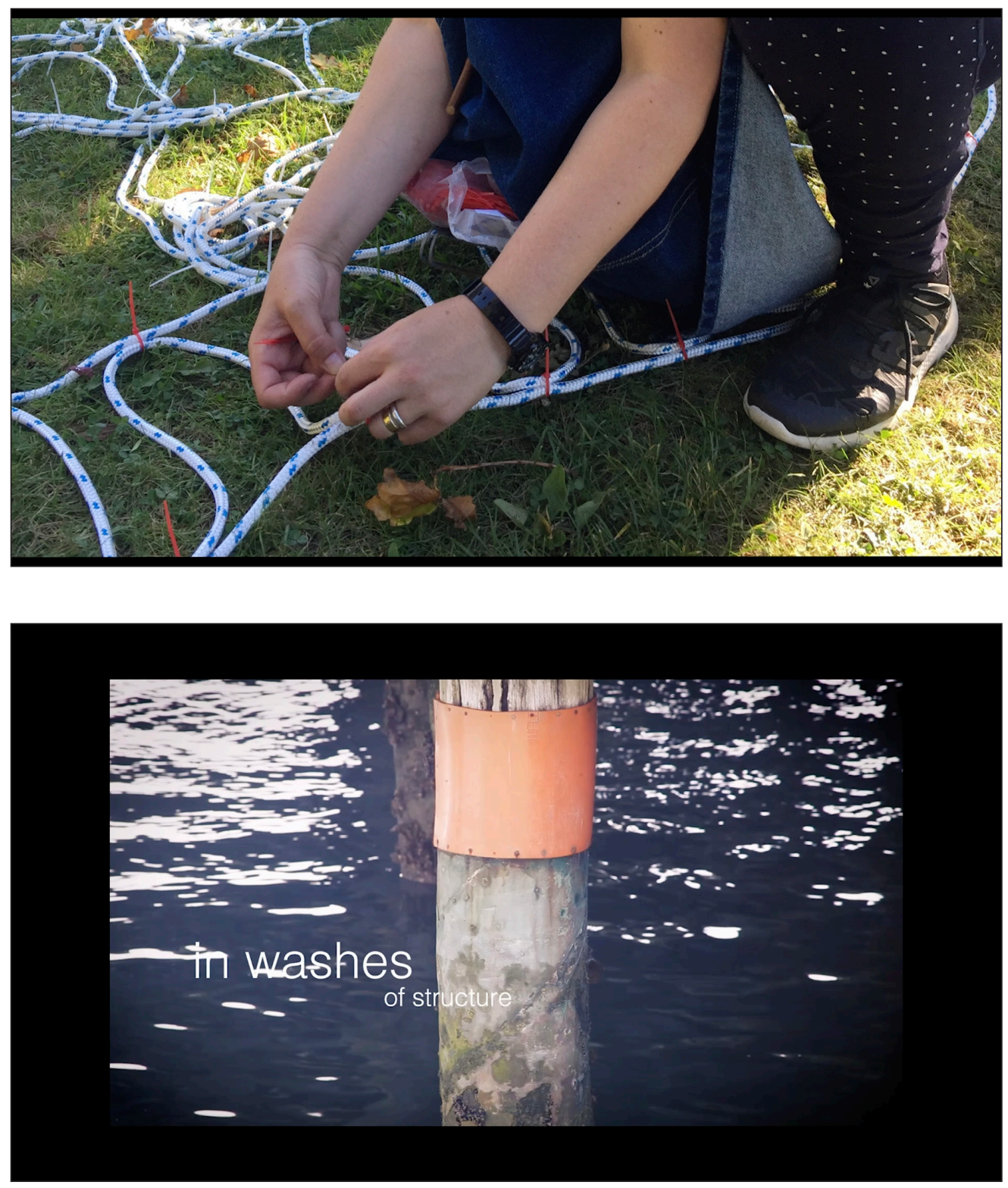

Journal of Embodied

Research

DOI: $10.16995 /$ jer.34

\section{VIDEO ARTICLE TRANSCRIPT}

[Note: This is a transcript of a video article. Individual elements from the transcript, such as metadata and reference lists, may appear more than once in the document, in order to be properly read and accessed by automated systems. The transcript can be used as a placeholder or reference when it is not possible to embed the actual video, which can be found by following the DOI.]

[00:10]

Dr Alys Longley

National Institute of Creative Arts and Industry

The University of Auckland

[Alys:]

You sit and write at the coastline. You are noticing how the beach is both ground and not-ground, land and not-land. Especially now, in this time of rising seas. All sorts of things are getting washed in and washed up. Falling ashore. Thinking about what happens when the ocean turns on you. So tender and so unsympathetic. This body in which you are such a part, this body that could digest you in a moment, this body of unimaginable force and density, this body of liquid perception, leaving a skin of salt. 
Touching Outward: Art-making at the seam where care meets risk

Dr Alys Longley

Gabby O'Connor

Dr Karen Fisher

James Hutchinson

As authors of this article, we are all islanders, we have always lived on islands. We are used to having a view of the sea amongst daily life. To read the palette as salt-tones wash is to read everything as vibration. The weather reaching and morphing across us all. The horizon is non-binary, it bleeds its atmospheres to varying degrees.

"Matter is condensations of response-ability" (Karen Barad, 2019).

"Time folds

and your actions matter

in all directions"

[01:35]

James Hutchinson

Artist/Filmmaker

[James:]

We are four artist-researchers from diverse disciplinary backgrounds, each of us working beyond our conventional practices: a geographer, a performance maker, a visual artist, and a filmmaker. We are moving between philosophy, social science, pedagogy, ecology, performance, poetry, installation and film.

philosophy, social science, pedagogy, ecology, performance, poetry, installation, film.

The framework of weak theory provides a kind of permission to reach beyond the conventions of our disciplines, to make space for modes of embodied research that entangle abstract and material concepts through relational, artistic and pedagogical intentions.

Artistic methods form the core this embodied research - from our different backgrounds, we aim to employ practices that allow space for complex ideas to move in a language which is fluid, spacious, and affective. We employ poetic and visual forms in ways that aim to provoke rather than explain, to encourage those who encounter our work to form a felt relationship with it. Embodied research entwines with visceral, sensory, haptic, and spatial modes of relation.

[02:48]

Dr Karen Fisher

School of Environment

University of Auckland

We think about drawing attention to the co-extensiveness of human bodies with all the other bodies - with environments, animals, bacteria, insects, atmospheres, objects, ecologies.

\section{ENVIRONMENTS}




\section{OBJECTS}

\section{ECOLOGIES}

This article explores two iterations of an art practice that emerged through the research project Navigating Marine Social-Ecological Systems.

Navigating Marine Social-Ecological Systems.

We are researching how human communities in Nelson, Aotearoa New Zealand, understand risk in relation to their extended marine environments. We are thinking about the nature of touch and considering sound as a kind of touching outward:

what it is to touch?

how far can our care reach?

Our embodied practice as artists and researchers stretches out to you, as you experience this video article, through the touch-practice of sound and through the visual practice of image making. Body to body. Vibration to vibration. Across time. Thinking time as a fluid, through practices of art, philosophy, writing, speech.

\section{[Alys:]}

If we think with, and take seriously a fluid ontology, can we recognise embodiment itself as fluid? Drenched with unknowing and drenched with sensation and made possible by movement, vibration, and magnetism.

The wonderful thing about this body is that the fluid that makes up around $70 \%$ of it has been consistently recycled since this earth began. There's this very slow duration water cycle enabling the production of this voice, as it touches out to your ears.

In making a valid contribution to the Journal of Embodied Research, is it necessary that we feature the fleshy forms of human bodies?

Or might we think of bodies in other ways?

[04:56]

[Karen:]

We perceive the body of the oceans as facing multiple, complex risks. And we are bringing the embodied resources of our practices as artists and social scientists to explore these risks through the following research question:

"How might we engage artistic processes to better understand actual and perceived risks to marine sustainability and facilitate community engagement, beyond the circulation of scientific publication?"

How might we engage artistic processes to better understand actual and perceived risks to marine sustainability and facilitate community engagement, beyond the circulation of scientific publication? 
[Alys:]

We are moving in the seam between art and science.

Artistic Map 1.

The Unseen

Artistic Map 2.

Every Accumulation Shifts the Music of Things

This video article presents two artistic maps, iterations of a single project exploring methods for engaging diverse publics to imagine, feel, consider and care about marine-related issues of risk which impact oceans and coastlines.

These artistic maps explore institutional, social and cultural factors influencing coasts and oceans in Aotearoa New Zealand.

Embodiment is at the heart of these collaborative projects. We think of how embodied experience folds through imagination to create potentials for unseating convention, perspective, actuality, reproducibility, common sense.

We're focusing on how creative processes may initiate forms of engagement in social-ecological research.

[06:20]

[Karen:]

Artistic mapping is a creative methodology for visualising worlds in unconventional ways, articulating complex social, cultural and geopolitical issues.

Social

Cultural

Geo political

(Duxbury et al. 2018)

We propose that artistic mapping is a valuable tool in interdisciplinary sustainability research as it provides a means to work across diverse settings and ontologies.

Imaginary

Reality

Possibility

Exploring artistic and cultural mapping allows space for the imaginary - wherein the spaces between reality and possibility are made porous and interlayered.

[06:50]

[Alys:]

We propose that merging writing in the expanded field with artistic mapping

can enable alternative views and modes of thinking.

in the expanded field 
We want to emphasise political and critical vitality, and to make poetic, tactile and spatial maps to chart space, time, experience, relationships, ecologies, moments and concepts.

"We might now talk about 'writing in the expanded field', a field in which writing's conventional autonomy - that is its objectivity, its truthfulness and its transparency - is in question, as writing has opened out fully into its material and conceptual contexts ... in this expanded field language has weight, and it has material and visual 'freight'. It has graphic presence that also 'carries' meaning. Language can act as a form of dynamic exchange, a powerful conduit between the material and metaphysical or conceptual." (MacDonald, 2009, p. 100)

Artistic interventions into the field of mapping may bring unprecedented connections between the material and the abstract, the actual and the virtual, the tangible and the intangible, the objective and the felt.

Artistic interventions into the field of mapping may bring unprecedented connections between the material and the abstract, the actual and the virtual, the tangible and the intangible, the objective and the felt.

Artist-academic Paul Carter proposes that "an important emotional landmark in any cultural mapping project should be the reenactment of strangeness, the encounter with the inexplicable that commands a new self-awareness." Maps are formed by conventions and values. Artists can rewrite these through questioning, juxtaposition, and disruption of accepted models.

Artistic maps create space for dwelling-with the concepts which they map, working with felt affect rather than accountable truth, evoking complex, interconnected relationships between ecological elements.

"Maps are tools to capture the incomprehensible, unconscious or structurally "invisible" qualities of space. What they describe is the basis for new realities. As maps both disclose and re-shape what is already in experience, they give it meaning and introduce new layers of perception."

"Maps are tools to capture the incomprehensible, unconscious or structurally "invisible" qualities of space. What they describe is the basis for new realities. As maps both disclose and re-shape what is already in existence, they give it meaning and introduce new layers of perception."

(An Architektur with a42.org. Geography of the Fürth Departure Centre, 2007).

Our methodology also draws on weak theory as a critical frame to enable collaborative, interdisciplinary practice.

Weak Theory

Geographer Sarah Wright draws on the work of [Eve Kofosky] Sedgwick and Sylvan Tomkins to define weak theory:

Where strong theory demands comprehensiveness, exclusivity and grand claims, weak theory supports partial understandings and multiplicity, and allows for both contradictions and inconsistency.

"Where strong theory demands comprehensiveness, exclusivity and grand claims, weak theory supports partial understandings and multiplicity, and allows for both contradictions and inconsistency" (Wright, 2015, p. 192). 
[Karen:]

Navigating Marine Social Ecological Systems is a transdisciplinary research project investigating the institutional, social and cultural factors influencing the governance and management of coasts and oceans in Aotearoa New Zealand.

Institutional

Social

Cultural

New Zealand Government

Te Wānanga o Aotearoa

Ministry of Business,

Innovation and Employment

Hīkina Whakatutuki

National Science Challenges

Sustainable Seas

Ko ngā moana whakauka

Tangaroa

Valuable Seas

Dynamic Seas

Managed Seas

Our Seas

Vision Matauranga

Cross Platform

Testing participatory processes for marine management

Frameworks for Achieving and maintaining social license

Navigating Marine Social-ecological systems

Participatory systems for marine ecosystem restoration

Enabling Inter-agency collaboration on cumulative effects

TRUST

Cumulative Effects (Marine Management)

RISK

The Unseen

Every Accumulation

To enhance the utilisation of marine resources within environmental and biological constraints; and, to improve decision-making and the health of our seas through ecosystem-based management.

Ecosystem based management is a holistic and inclusive way to manage marine environments and the competin uses for, demands on, and ways New Zealanders value them. 
We are one of a tiny group of artist-researchers with a project dominated by scientists and social-sciences, engaging creative practice to stimulate critical reflection and action.

Critical reflection

Action

We understand hope as a disposition that can generate feelings of possibility and seek to examine how bodies become hopeful and how hope and care are "entangled in the circulation, and displacement, of other affects and emotions."

\section{HOPE}

Possibility

Bodies become hopeful

Hope is "entangled in the circulation, and displacement, of other affects and emotions".

Hope signals the possibility that the "spatial/temporal here and now may become otherwise" (Anderson and Fenton, 2008, p. 76).

Hope signals the possibility that the "spatial/temporal here and now may become otherwise." Becoming hopeful involves an individual being attuned to the ability to affect and be affected by the emotional and affectual processes within which they are enmeshed and to imagine their futures otherwise.

as a way to avoid the pessimism and foreclosing of possibility that can come when considering environmental change

We adopt this disposition as a way to avoid the pessimism and foreclosing of possibility that can come when considering environmental change from a risk perspective. Risk has been defined in multiple ways. Examples include risk as an expected value, a probability distribution, as uncertainty, and as an event.

\section{RISK}

Risk as expected value

Risk as probability

Risk as distribution

Risk as uncertainty

Risk as an event

Harm

Loss

RISK

Pollution

Habitat and Species Loss

Ocean Temperature and Acidity

In our work, we see risk as the potential for exposure to harm and loss, and focus on how the social and cultural context and personal experiences influence how people understand and respond to risk. 
Artistic Map 1.

THE UNSEEN

Gabby O'Connor

Artist

[Gabby:]

A core element of Gabby O'Connor's work, The Unseen, was embodied collaboration between young people, artists and scientists to make an artwork - manipulating rope, tracing spaces, moving fluidly in conversations and spaces of inquiry.

The pairs paired up, joining their rope art together.

The process of making together through shared kinesthetic practice develops space for co-created ideas.

These independent ideas are then woven into a larger whole, mapping bodies of interaction, listening and response.

The independent ideas are then woven into a larger whole, mapping bodies of interaction, listening and response.

1600 people have participated in one of 37 workshops to produce the multiple collaborative artworks that become The Unseen, an art, science and community project in Nelson, New Zealand.

The Unseen considers audience as an ecosystem. An ecosystem of communities considering their local marine space, how it is being researched, measured and understood. And how it is changing. The collective artwork created functions as a map. A maps of our thoughts, our understanding and cooperation, of understanding our watery spaces, our interconnected ecosystems. And of hope, of imagining futures.

HOPE

Together we co-create knowledge maps, embody complex information from a wide range of subject areas delivered through story telling about our marine space.

And we start with place. A place that the participants know. Our stories are rich with knowledge and there is space to fold in everyone's experiences.

What was the coolest thing that you discovered about the marine environment?

That there are blob fishies.

The different layers of the sea and what creatures live there.

That there is a machine that can find out the ocean's temp.

I discovered that there are heaps of different layers in the ocean.

That I like seals \& that fish aren't scary

Stuff about fish

how deep the water could go and i enjoyed making pichers with Ropes

that seals have snot 
Water glider rocker and how it comes into the water and above +0 discover the planet of the ocean

that there are different layers and whales can go through nearly all of them

That Plankton can't change levels

The Water glider thing

How the ice forms

the robots they use for research

the different level sof the ocean

That there are different layers and some fish can't pass through

That there are different levels in the sea

There are leaves in the sea some light and some dark

the robot

the circles

The ice crystals

Seals snot everywhere when they come up to breathe

If you could research anything about the marine environment (using art or science or both) what would you do?

Study the blob fish.

Paca paranahs Amazon.

corals

I would research Otters

(I don't like research) Who eats who?

Who eats who?

Reshrsh sharks and lots of under water fish

Look at all of the sea life

Antarcar, and marine Science

I would research how ice Particles are made in antartica

Fish migration

I would research anything!

I would research otters.

reserch about the Robot

worl pool

I would research ice bergs

Ice sculpturs

How fish can't get though sea leavels

I don't know

Paint the sea

Coral reefs

How some fish can't get through sea levels 
This art practice enables communities to with participate in and engage with conversations about marine science in the place in which they live.

Geographically separate communities are connected through these maps. We traverse, navigate and connect with these maps. With its ropey lines, drawing all that we can in time and space. With care we place it in the landscape. With care we reflect on our experience. Expansive thinking likes space, to deepen our understanding. And consider our future.

The Unseen

by Gabby O'Connor

Albion Square - March 28th - April 7, 2018

Carolyn Lundquist, Di Tracey, Victoria Warren, Joe O'Callaghan, Vonder Cummings

Clifton Terrace School, Hira School, Hope School, St Joseph's School, Auckland Point School, Victory School, Nelson Central School, Hampden St School, Canvastown School, Rai Vallet Area School, Stoke School, Tahunanui School, Nayland School, Hataitai School, Newtown School, The Suter Art Gallery, Hutt War Memorial Library, Canterbury University School of Fine Arts, The Physics Room, Handshake 4 Jewellers

Artistic Map 2.

Every Accumulation Shifts the Music of Things

[Karen:]

Every Accumulation Shifts the Music of Things is an experiment in artistic mapping which makes a creative attempt to map - through filmmaking and creative writing the intangible physical and emotional landscapes of risk, related to key issues in our Sustainable Seas research project.

Nelson

This video visually alludes to a range of potentially "risky stuff" related to the research site at the core of this project: fisheries, orchard run-off, forestry, agriculture, neo-productive landscapes, dairy farming, mixed land use and climate change.

Fisheries,

Orchard run-off,

Forestry,

Agriculture

Neo-productive landscapes,

Dairy farming,

Mixed land usem

Climate change.

This poetic work translates language drawn from marine science such as "cumulative effects" and "tipping points" to generate a poetic logic, which is organised around imagery drawn from the sites where the marine scientists are working, to track the sustainability of New Zealand seas. This video asks you to consider the bodies of creatures that can't be seen, but with whom we co-create the world. 
in washes of structure

[Alys:]

At The Unseen workshop, I worked with a composer. Discussions of cumulative effects merged with ideas around accumulation scores in dance and music - which merged with our understanding of how plumes of nitrogen spool in the water, unsettling esturaine homes and the dwellings of many species of crab, as toxic fertilizers run off from orchards and farming.

Roots binding and unbinding nutrients

Microbes accumulating and dispersing in tipping points

in plumes, in washes

of structure

2.

Ropes spiralling through the water

3.

These tides of unintended consequences

flood Riwaka

and the silt has this almost musical process of accumulation

the building and falling, the rain so torrential

the distances between things tell

new notes of containment and level

but what about the breathing of all those living things requiring

particular densities of ground? The various environments of earth make homes we cannot feel. Homes we can only imagine based on observation, in which we cannot dwell. Yet every dwelling matters. Every accumulation shifts the music of things. You hold the word consequential in your mouth and it tastes like the clarity of sea water changing tune, the slight difference for swimming or for a fishes' breathing, the slight tip that can't be seen at all

Tipping Points

Plumes

Accumulating

As we looped the ropes, we considered the dwelling of insects and non-human species and their disrupted eco-systems - from natural state, to forested state, to a harvested state. The species that dwell in a disrupted eco-system are having to learn how to re-dwell each time. If humans continue to plant again, the cycle continues and each time different.

Microbes accumulating and dispersing

tipping points

in plumes,

flood

Riwaka 
[Karen:]

Each time the landscape is changed, an ecology is changed. The disruption to dwellings on land is mirrored in disruptions to dwellings in estuaries and seas.

As we loop the rope, we consider the liminality of sediment. It's soil that's been mobilised by water and it travels, it becomes a sign of erosion or degradation.

what about the breathing of all those living things requiring

particular densities of ground?

The various environments of earth make

homes we cannot feel.

Homes we can only imagine based on

observation,

As we filmed, we focussed on these landscapes as bodies, and on the lively, nonhuman bodies that are implicated in our changing marine environments. Coiling ropes, fishing boats, forestry, orchard work.

We chose to have two voices read the poem and to work with tonality, volume, speed, and duration as accumulating elements, to engage the musicality of voice and language as an abstract quality.

In this way, we carefully considered how sound and tonality touch out to the listener.

"Touch isn't about something... Sound is touch at a distance."

"Sound is touch at a distance" (Anne Fernald, cited in RadioLab, 2007).

Every Accumulation Shifts the Music of Things

There are these cumulative stressors

Roots binding and unbinding nutrients

Microbes accumulating and dispersing in tipping points

in plumes, in washes

of structure

Ropes spiralling through the water

These tides of unintended consequences

flood Riwaka

and the silt has this almost musical process of accumulation

the building and falling, the rain so torrential

the distances between things tell

new notes of containment and level

but what about the breathing of all those living things requiring 
particular densities of ground? The various environments of earth make homes we cannot feel. Homes we can only imagine based on observation, in which we cannot dwell. Yet every dwelling matters.

Every accumulation shifts the music of things. You hold the word consequential in your mouth and it tastes like the clarity of sea water changing tune, the slight difference for swimming or for a fishes' breathing, the slight tip that can't be seen at all but that forecasts a barely imaginable tideline, carrying the roots of an apple tree upon a curving, endless surface

Nelson

(Whakatū)

Every Accumulation Shifts The Music of Things

by James Hutchinson, Alys Longley, Karen Fisher

Cinematography, Editing, Design by James Hutchinson

Poem by Alys Longley

Sound by Jeffrey Holdaway

Poem Read by Alys Longley, Robbie McEwan

Research Team Alys Longley, James Hutchinson, Karen Fisher, Kate Davies, Libby Shore
Longley et al.

\section{[James:]}

Every Accumulation has many shots with an unmoving camera, a strong formal composition, and moving water. A tidal sense of time moves visually and poetically throughout the work. There is a play between the evocation of specific landscapes and their relationship to environmental risk.

Artistic Map 1.

The Unseen

Artistic Map 2.

Every Accumulation Shifts the Music of Things

[Alys:]

These artistic maps align with Paul Carter's emphasis on the "re-enactment of strangeness" in cultural mapping. We frame the value of this work as enabling, as Jane Bennett describes, "a counter-cultural form of perceiving." In doing this research, we take seriously the idea that "learning is a process of emergence and co-evolution of the individual, the social group and the wider society" [Giouvanakis et. al., 2010, p. 17]. These experiments in arts-science-education research, find hope in spaces of imagination, creativity and collaboration, as they provide an alternative punctuation within a world of increasing risk and uncertainty.

Hope signals the possibility that the "spatial/temporal here and now may become otherwise" (Anderson and Fenton, 2008, p. 76) 
Dr Karen Fisher

Dr Alys Longley

Gabby O'Connor

James Hutchinson

Additional Photography

Wetland cows wairarape credit Dave Allen NIWA

Devon St Slip credit Erika Mackay NIWA

FoxtonFlood credit_Alan_Blacklock NIWA

Haumoanamarch2005_credit_Alan Blacklock NIWA

KelsonSlip credit_Alan_Blacklock_NIWA

Rain credit_Dave_Allen_NIWA

Red_clay_erosion - sediment_plume_in Lake Superior - epa.gov

River pollution credit_Dave_Allen NIWA

sea_credit_peter_marriott NIWA

Storm_wellington_south_coast credit Dave_Allen NIWA

Towering cumulus and shelf cloud thunderstorm credit Dave Allen NIWA

\section{ABSTRACT}

Touching Outward; Art-making at the seam where care meets risk

What it is to touch? If we think with, and take seriously a fluid ontology, can we recognise embodiment itself as fluid? Drenched with unknowing and drenched with sensation and made possible by movement, vibration and magnetism.

This video article engages with the potentiality for research in marine sustainability to develop through poetic logics, visual, filmic, relational art practices that bring diverse communities into conversation, to ask; "How might we engage artistic processes to better understand actual and perceived risks to marine sustainability and facilitate community engagement, beyond the circulation of scientific publication?

Touching Outward; Art-making at the seam where care meets risk presents two artistic maps, iterations of a single project that explores methods for engaging diverse publics to imagine, feel, consider and care about marine-related issues of risk which impact oceans and coastlines.

These artistic maps explore institutional, social and cultural factors influencing coasts and oceans in Aotearoa New Zealand. Embodiment is at the heart of these collaborative projects. We think of how embodied experience folds through imagination to create potentials for unseating convention, perspective, actuality, reproducibility, common sense.

Our transdisciplinary project was developed by four artist-researchers from diverse disciplinary backgrounds, each of us working beyond our conventional practices- a geographer, a performance maker, a visual artist, and a film maker. We are moving between philosophy, social science, pedagogy, ecology, performance, poetry, installation and film. The framework of weak theory provides a kind of permission to reach beyond the conventions of our disciplines, to make space for modes of embodied research that entangle abstract and material concepts through relational, artistic and pedagogical intentions.

Throughout the process and development of this artistic research, we question where a body begins and ends, how the voice as a vibratile force touches through time and space, and how moving image as a body of textures and cuts might contribute to methods of weak theory (Wright, 2015) and transdisciplinary creative practice. 


\section{KEYWORDS}

Marine Sustainability

Ecology

Risk

Poetic Inquiry

Transdisciplinary Research

Weak Theory

Oceans

Thinking with Water

Sound as Touch

National Science Challenges

Sustainable Seas

Ko ngā moana whakauka

sustainableseaschallenge.co.nz

The University of Auckland

Te Whare Wānanga o Tāmaki Makaurau

New Zealand

NIWA

Taihoro Nukurangi

\section{COMPETING INTERESTS}

The authors have no competing interests to declare.

\section{AUTHOR AFFILIATIONS}

Alys Longley (D) orcid.org/0000-0002-7687-6290

University of Auckland, NZ

Karen Fisher (D) orcid.org/0000-0002-1774-4431

University of Auckland, NZ

Gabby O'Connor (D) orcid.org/0000-0001-7130-1511

University of Auckland, NZ

James Hutchinson

Reasonable People, NZ

\section{BIBLIOGRAPHY}

Ambrose, D. (2014). Seeking chaotic order: The classroom as a complex adaptive system. DOI: https://doi. org/10.1007/978-94-6209-773-5_10

An Architektur with a42.org. (2007). Geography of the Fürth Departure Centre. In Atlas or Radical Cartography, L. Mogel \& A. Bhagat (Eds.). Los Angeles: Journal of Aesthetics \& Protest Press.

Barad, K. M. (2007). Meeting the universe halfway: quantum physics and the entanglement of matter and meaning. Durham: Duke University Press 2007. DOI: https://doi.org/10.1215/9780822388128

Barad, K. (2018). On Touching: The Alterity Within. Reach out and touch (Somebody's Hand): Feel Philosophies, Stedelijk Museum, Amsterdam, Curator, Jack Halberstam, 21-24 March, 2018, Retrieved 14 November 2019 from: https://www.youtube.com/watch?v=u7LvXswjEBY.

Bennett, Jane. (2010). Vibrant Mattter. A Political Ecology of Things. Durham and London: Duke University Press. DOI: https://doi.org/10.1515/9780822391623 
Boykoff, M. T. (2019). Creative (climate) communications: productive pathways for science, policy and society. DOI: https://doi.org/10.1017/9781108164047

Cilliers, P. (2002). Complexity and postmodernism understanding complex systems. London, New York: Routledge 2002. DOI: https://doi.org/10.4324/9780203012253

Carter, P. (2009). Dark Writing: Geography, Performance, Design. Honolulu, HI: University of Hawaii Press. DOI: https://doi.org/10.21313/hawaii/9780824832469.001.0001

Coker, J. S. (2017). Pedagogy and place in science education. DOI: https://doi.org/10.1007/978-3-31950621-0_6

Country, B., Wright, S., Suchet-Pearson, S., Lloyd, K., Burarrwanga, L., Ganambarr, R., ... Sweeney, J. (2016). Co-becoming Bawaka: Towards a relational understanding of place/space. Progress in Human Geography, 40(4), 455-475. DOI: https://doi.org/10.1177/0309132515589437

Duxbury, N., Garrett-Petts, W., Longley, A. (2018). Artistic Approaches to Cultural Mapping; Activating Imaginaries and Means of Knowing. London, UK: Routledge. DOI: https://doi. org/10.4324/9781315110028

Giouvanakis, T., Fragidis, G., Ignatiadis, I. Koumpis, A. (2010). myCourse: An Educational Content Management Platform with Social Networking Characteristics. International Journal of Emerging Technologies in Learning, 5(4), 17-26. DOI: https://doi.org/10.3991/ijet.v5i4.1450

Gibson-Graham, J. K. (2014). Rethinking the Economy with Thick Description and Weak Theory. Current Anthropology, 55(S9), S147-S153. DOI: https://doi.org/10.1086/676646

Harding, A. (2005). Magic moments: collaboration between artists and young people. London: Black Dog.

Hayward, B. (2017). Sea change: climate politics and New Zealand. Wellington: Bridget Williams Books. 2017. (C2017. DOI: https://doi.org/10.7810/9781988533285

Ingold, T. (2008). Bindings against Boundaries: Entanglements of Life in an Open World. Environment and Planning A, 40(8), 1796-1810. DOI: https://doi.org/10.1068/a40156

Lawson, D. F., Stevenson, K. T., Peterson, M. N., Carrier, S. J., Strnad, R. L., \& Seekamp, E. (2019). Children can foster climate change concern among their parents. Nature Climate Change. DOI: https://doi. org/10.1038/s41558-019-0463-3

Lawson, V. (2007). Geographies of Care and Responsibility. Annals of the Association of American Geographers, 97(1), 1-11. DOI: https://doi.org/10.1111/j.1467-8306.2007.00520.x

Little, R. (2014). Art, Place, Climate: Situated Ethics. In M. P. (Ed.), Ethics and the Arts. Dordrecht: Springer. DOI: https://doi.org/10.1007/978-94-017-8816-8_21

Plumwood, V. (1998). Knowledge in an Ethical Framework of Care. Australian Journal of Environmental Management, 5(sup1), 27-38. DOI: https://doi.org/10.1080/14486563.1998.10648434

MacDonald, C. (2009). How to Do Things with Words: Textual Typologies and Doctoral Writing. Journal of Writing in Creative Practice, 2(1): 91-103. DOI: https://doi.org/10.1386/jwcp.2.1.91_1

Radiolab. (2007). Sound as Touch. Radiolab Podcast. September 4, 2007. Retrieved 10 November 2019 from: https://www.wnycstudios.org/podcasts/radiolab/segments/91514-sound-as-touch

Rose, G. (1997). Situating knowledges: positionality, reflexivities and other tactics. Progress in Human Geography, 21(3), 305-320. DOI: https://doi.org/10.1191/030913297673302122

Tronto, J. C. (1993). Moral boundaries: a political argument for an ethic of care. New York: Routledge 1993.

Trott, C. D. (2019). Reshaping our world: Collaborating with children for community-based climate change action. Action Research, 17(1), 42-62. DOI: https://doi.org/10.1177/1476750319829209

Watson, R. (2018). Mapping and Contemporary Art. In N. Duxbury, W. Garrett-Petts \& A. Longley (Eds.), Artistic Approaches to Cultural Mapping; Activating Imaginaries and Means of Knowing. London, UK: Routledge. DOI: https://doi.org/10.4324/9781315110028-2

Wright, S. (2015). More-than-human, emergent belongings: A weak theory approach. Progress in Human Geography, 39(4), 391-411. DOI: https://doi.org/10.1177/0309132514537132
Longley et al.

Journal of Embodied

Research

DOI: $10.16995 /$ jer.34
TO CITE THIS ARTICLE: Longley, A, Fisher, K, O'Connor, G and Hutchinson, J. 2021. Touching Outward: Art-Making at the Seam Where Care Meets Risk. Journal of Embodied Research, 4(1): 1 (21:14). DOI: https://doi.org/10.16995/jer.34

Submitted: 10 March 2020 Accepted: 07 November 2020 Published: 05 February 2021

COPYRIGHT:

(c) 2021 The Author(s). This is an open-access article distributed under the terms of the AttributionNonCommercial-NoDerivatives 4.0 International License (CC BY-NC-ND 4.0), which permits unrestricted use, distribution, and reproduction in any medium, provided the original author and source are credited. See $h t t p: / / c r e a t i v e c o m m o n s$. org/licenses/by/4.0/.

Journal of Embodied Research is a peer-reviewed open access journal published by Open Library of Humanities. 